\title{
Diagnosis and management of adhesive capsulitis
}

\author{
Robert C. Manske · Daniel Prohaska
}

Published online: 23 May 2008

(C) The Author(s) 2008

\begin{abstract}
Adhesive capsulitis is a musculoskeletal condition that has a disabling capability. This review discusses the diagnosis and both operative and nonoperative management of this shoulder condition that causes significant morbidity. Issues related to medications, rehabilitation, and post surgical considerations are discussed.
\end{abstract}

Keywords Adhesive capsulitis - Shoulder pain ·

Surgery

\section{Introduction}

The shoulder is a unique anatomical structure with an extraordinary range of motion (ROM) that allows us to interact with our environment. A loss of mobility of this joint will cause significant morbidity. Adhesive capsulitis is a poorly understood musculoskeletal condition that can be disabling. Adhesive capsulitis is diagnosed by numerous physical characteristics including a thickening of the synovial capsule, adhesions within the subacromial or

R. C. Manske ( $\square)$

Department of Physical Therapy, Wichita State University, 1845 North Fairmount, Wichita, KS 67260-0043, USA

e-mail: Robert.manske@wichita.edu

\section{R. C. Manske}

Department of Family Medicine, Sports Medicine Fellowship Program, University of Kansas School of Medicine, Wichita, KS, USA

\section{Prohaska}

Department of Orthopaedics, Advanced Orthopaedic Associates, University of Kansas School of Medicine-Wichita, 2778 N.

Webb Rd., Wichita, KS 67226, USA

e-mail: dprohaska@kumc.edu subdeltoid bursa, adhesions to the biceps tendon, and/or obliteration of the axillary fold secondary to adhesions [1-9]. Since Duplay initially described a case report of adhesive capsulitis almost 130 years ago, this condition remains an enigmatic shoulder disorder that causes pain and restricted ROM at the glenohumeral joint [10].

\section{Incidence}

Adhesive capsulitis has an incidence of $3-5 \%$ in the general population and up to $20 \%$ in those with diabetes. This disorder is one of the most common musculoskeletal problems seen in orthopedics [11-15]. Although some have described adhesive capsulitis as a self-limiting disorder that resolves in 1-3 years [13, 16-20], other studies report ranges of between 20 and $50 \%$ of patients with adhesive caspulitis which suffer long-term ROM deficits that may last up to 10 years [21-25].

The typical patient that develops adhesive capsulitis is a female in her 5 th to 7 th decade of life [17, 23]. There is generally no preference for handedness and adhesive capsulitis rarely occurs simultaneously bilaterally [17, 23]. However, others have reported that it can occur sequentially bilaterally in up to $40-50 \%$ of patients [26]. Adhesive capsulitis is commonly associated with other systemic and nonsystemic conditions. By far the most common is the co-morbid condition of diabetes mellitus, with an incidence of $10-36 \%$ [14, 27, 28].

Other co-morbid conditions include hyperthyroidism, hypothyroidism, hypoadrenalism, Parkinson's disease, cardiac disease, pulmonary disease, stroke, and even surgical procedures that do not affect the shoulder such as cardiac surgery, cardiac catheterization, neurosurgery, and radical neck dissection [29-39]. 
Wolf and Green [40] prospectively evaluated 100 consecutive patients with adhesive capsulitis with use of several forms of questionnaires. Patients with more comorbidities had significantly lower and poorer scores on shoulder assessment forms, social function, and emotional and mental health.

\section{Adhesive capsulitis classification}

Adhesive capsulitis is classified into two categories: (1) primary, which is insidious and idiopathic, or (2) secondary, which is generally due to trauma or subsequent immobilization [41]. Those with primary adhesive capsulitis generally have a very gradual onset and progression of symptoms, with no known precipitating event that can be identified [42]. These symptoms may progress so slowly that the patient does not even seek medical attention until ROM and pain severely limit their daily activities. It is not uncommon for a patient to present with shoulder pain as their only complaint and not realize there is a loss of motion. This is unlike the person afflicted with a secondary adhesive capsulitis who usually notices their symptoms soon after a fall or inciting trauma as their ROM does not appear to improve as expected after the pain from the inciting event should no longer limit ROM.

\section{Clinical phases}

Adhesive capsulitis presentation is generally broken into three distinct stages [43]. The first stage that is described is called the freezing or painful stage. Patients may not present during this stage because they think that eventually the pain will resolve if self-treated. As the symptoms progress, pain worsens and both active and passive ROM becomes more restricted, eventually resulting in the patient seeking medical consultation. This phase typically lasts between 3 and 9 months and is characterized by an acute synovitis of the glenohumeral joint [44].

Most patients will progress to the second stage, the frozen or transitional stage. During this stage shoulder pain does not necessarily worsen. Because of pain at end ROM, use of the arm may be limited causing muscular disuse. The frozen stage lasts anywhere 4 to 12 months [44]. The common capsular pattern of limitation has historically been described as diminishing motions with external shoulder rotation being the most limited, followed closely by shoulder flexion, and internal rotation. There eventually becomes a point in the frozen stage that pain does not occur at the end of ROM.

The third stage begins when ROM begins to improve. This 3rd stage is termed the thawing stage. This stage lasts anywhere from 12 to 42 months and is defined by a gradual return of shoulder mobility.

\section{Pathology}

Pain associated with adhesive capsulitis can cause a limitation or selective immobilization of the painful shoulder. Prolonged immobilization of a joint has been shown to cause several detrimental pathophysiologic findings including: decreased collagen length, fibrofatty infiltration into the capsular recess, ligament atrophy resulting in decreased stress absorption, collagen band bridging across recesses, random collagen production, and altered sarcomere number in muscle tissue [45].

\section{Evaluation}

The evaluation of adhesive capsulitis starts with a thorough shoulder history. Inciting events such as mild trauma are often given in relation to the shoulder pain. This may be something very trivial, and in fact may not be related to the process, but the patient may recall something that is attributed to starting the process. Adhesive capsulitis often involves the non-dominant extremity. This is because it is easier to protect and not use the extremity because it is painful and the dominant extremity can do the work. When the extremity is held close to the body, often to "protect it", the process can then proceed unchecked. This becomes even more apparent when passive ROM is accompanied by an unusual amount of pain and guarding. Codman [18] discussed this entity describing a slow onset of pain, felt near the insertion of the deltoid, inability to sleep on the affected side, and restriction in both active and passive elevation as well as external rotation, yet with normal radiologic appearance. Without degenerative joint disease on radiographs, this clinical picture suggests the diagnosis of adhesive capsulitis.

The physical examination is marked by the loss of both passive and active range of motion. This motion may also be painful as the capsule reaches its stretching point. Examination tests for other shoulder abnormalities can also be positive. Testing for impingement may be positive with a Hawkin's or Neer sign; however, the pain is likely from the intrinsic process of impingement or capsular stretch rather than from adhesive capsulitis.

The diagnosis of adhesive capsulitis is often one of exclusion. Early in the disease process adhesive capsulitis may clinically appear similar to other shoulder conditions such as major trauma, rotator cuff tear, rotator cuff contusion, labral tear, bone contusion, subacromial bursitis, cervical or peripheral neuropathy. Additionally, a history of a previous surgical procedure can lead to shoulder 
stiffness. If a history of these other pathologies are negative and if radiographs do not demonstrate osteoarthritis, then the diagnosis can be given.

A screening radiograph of the shoulder is imperative to diagnose adhesive capsulitis. This rules out other possible diagnosis of loss of ROM that include osteoarthritis, or chronic anterior or posterior dislocation.

\section{Non-operative treatment}

\section{Anti-inflammatories}

Treatment of adhesive capsulitis often involves the use of anti-inflammatories, or corticosteroids. NSAIDs may be used during any phase as an attempt to relieve symptoms. There are no well done studies to indicate that NSAIDs change the natural history of adhesive capsulitis. There is a paucity of literature that even would support the use of NSAIDS for this diagnosis. However, NSAIDS are not only anti-inflammatories, they are analgesics and are a reasonable first choice for treatment.

A summary of studies related to oral corticosteroids can be seen in Table 1. There are no randomized studies comparing oral corticosteroids with placebo or natural history of the condition. Most studies seem to show that corticosteroids may reduce pain early on better than rehabilitation or placebo but their benefits are not maintained long term. Their risks and benefits therefore must be strongly considered before using them since long-term benefit is not supported. They may be considered when short-term gain is necessary for a particular event.

\section{Intra-articular corticosteroid injections}

Although high-quality randomized studies of corticosteroid injection for treatment of adhesive capsulitis have not been done, there is some evidence to indicate there is a short-term benefit with their use. Given the low likelihood of complications with this approach, the use of either a subacromial injection or glenohumeral injection should be considered. One limitation to using this form of treatment comes upon recent evidence that injections performed blindly may be inaccurate in approximately $60 \%$ of cases. Better clinical outcome is found with greater accuracy [46, 47]. This problem may be overcome with the use of ultrasound guided joint injection. Please see Table 2 for studies related to intra-articular cortisone injections for adhesive capsulitis.

\section{Capsular distension injections}

This method of treatment has been described for patients under local anesthesia. The joint is injected to its limits with local anesthetic to attempt to stretch the capsule. This technique is often poorly tolerated because of pain that is experienced during the process as the entire shoulder is not anesthetized from the intra-articular injection [48].

\section{Surgical treatment}

The treatment of adhesive capsulitis should lead to the operating room only after a concerted effort at conservative management has failed. There is not a discrete timeline to head to surgery. As a general rule patients should have participated in some form of therapy for at least 2 months, and shown no progress. Patients should feel they are not making progress and have significant pain and limitations of occupation, recreation, or sleep to proceed with surgical intervention.

\section{Manipulation under anesthesia}

Manipulation under anesthesia as a means of treatment has been advocated. This method allows return of ROM in the operating room. Immediate postoperative physical therapy can be initiated with this form of treatment [49]. Manipulation under anesthesia has the disadvantage in that tissues that are stretched while the patient is under anesthesia may cause pain when awake. This can potentially slow recovery. When surgical release is added to this procedure it induces further surgical trauma to the shoulder and may slow rehabilitation.

\section{Arthroscopic release and repair}

Arthroscopy is an excellent additional tool for addressing the shoulder with adhesive capsulitis, and has become well accepted in treating this process. The essential lesion is the tightened coracohumeral ligament and rotator interval with the contracted capsule including the axillary pouch. These structures can be treated by release with arthroscopic instruments. The contracted structures are released to allow ROM to return with manipulation if necessary. The release can be performed either before, during, or after the manipulation with favorable results (Fig. 1) [50-60]. The manipulation may need to precede the procedure to gain access to the joint. Arthroscopy allows a full evaluation of the shoulder anatomy as well. Any abnormalities that may not have been diagnosed and that may have contributed to the development of the condition can be addressed. This may make postoperative ROM less painful and recovery time decreased.

Operative treatment of adhesive capsulitis has been shown to decrease the duration of the disease and to return ROM with good success. Total recovery of pain-free ROM averages 2.8 months (1-6), and time for formal physical 
Table 1 Description of published randomized controlled trials of oral corticosteroids for adhesive capsulitis

\begin{tabular}{llll}
\hline $\begin{array}{l}\text { Study and date } \\
\text { published }\end{array}$ & $\begin{array}{l}\text { Number of } \\
\text { shoulders }\end{array}$ & Active intervention & $\begin{array}{l}\text { Control } \\
\text { intervention }\end{array}$
\end{tabular}

\begin{tabular}{ll}
\hline $\begin{array}{l}\text { Blockey and Wright } \\
\text { [62], } 1954\end{array}$ & Cortisone acetate $(200 \mathrm{mg}$ daily for \\
& 3 days, then $100 \mathrm{mg}$ daily for \\
& 11 days, then dose tapered off in \\
& decrements of $12.5 \mathrm{mg}$ every \\
& 2 days, total dose $=2.5 \mathrm{~g}$ over \\
& 4 weeks. If unsatisfactory progress \\
& after 4 weeks, manipulation under \\
& general anaesthesia; followed by a \\
& second 4 week course of cortisone \\
& acetate
\end{tabular}

Kessel et al. [63], $1981 \quad 32$

Binder et al. [23], 1986
Prednisolone (15 mg daily for 4 weeks) and manipulation (after 2 weeks of oral steroids)

Prednisolone (10 mg daily for 4 weeks, then $5 \mathrm{mg}$ daily for 2 weeks
Placebo

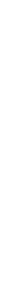

Manipulation

No treatment
No statistical analysis of between-group differences reported, although an earlier clinically important improvement in both pain and range of motion was noted in the oral steroid group: mean pain scores (measured on a 4-point categorical scale converted into an interval scale, where none $=0$, slight $=1$, moderated $=2$, severe $=3$ ) at baseline, 1,4 , and 18 weeks were $1.4,0.9,0.5,0.6$ in the steroid group, and 1.4, 1.3, 0.8, 0.5 in the control group; total shoulder abduction was $82,103,125,153^{\circ}$ in the steroid groups and $75,89,106,154^{\circ}$ in the control group. The number of participants requiring manipulation after 4 weeks was $6 / 15(40 \%)$ and $11 /$ $16(68.8 \%)$ in the steroid and placebo groups, respectively $(\mathrm{RR}=0.58$ (0.29-1.17))

No statistical analysis was done but "dramatic response" to manipulation in $7 / 12(58.3 \%)$ participants taking oral steroids compared with $5 / 16(31.25 \%)$ taking placebo. Effect of manipulation on final range of motion at 6,12 , and 18 weeks following the procedure also favored the steroid group but again the differences between groups were normally not formally analyzed

The pattern of improvement in pain at night over 8 weeks showed a significant difference in favor of oral prednisolone with a more rapid initial recovery, although by 5 months the difference between the groups was negligible. Improvement in pain at rest and with movement, range of motion, and a cumulative recovery curve were not significantly different between groups over 8 months

Greater improvement in overall pain in oral steroid group than in placebo group at 3 weeks. There was also greater improvement in disability, range of motion and participant rated improvement in 22/23 (96\%) oral steroid, vs. $11 / 23(48 \%)$ in placebo group. At 6 weeks, analysis favored the oral steroid group for most outcomes but none of the differences was significant. At 12 weeks, the analysis tended to favor the placebo group. A 3 week course of $30 \mathrm{mg}$ prednisolone daily is of significant short-term benefit in adhesive capsulitis but benefits are not maintained beyond 6 weeks 


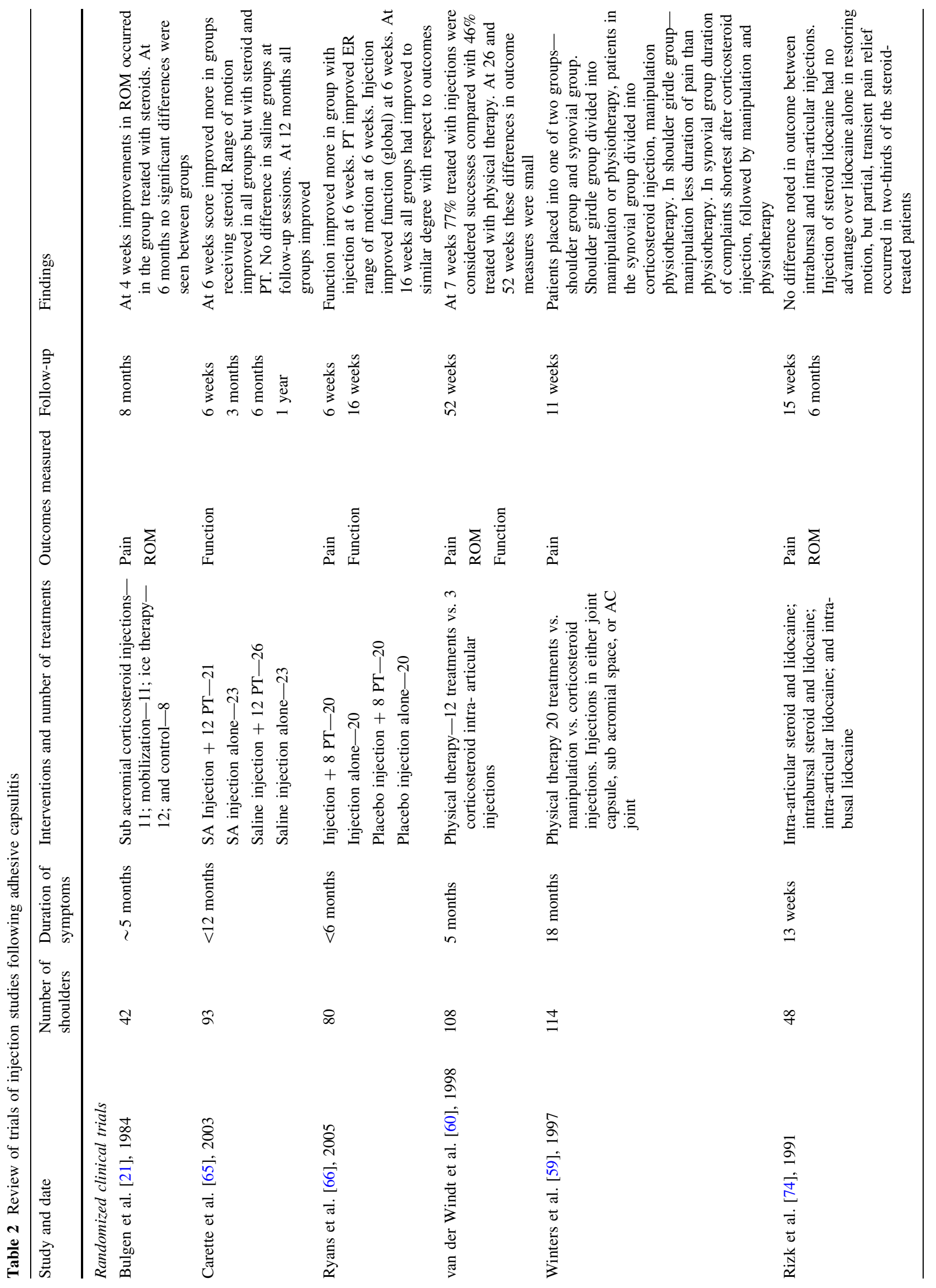




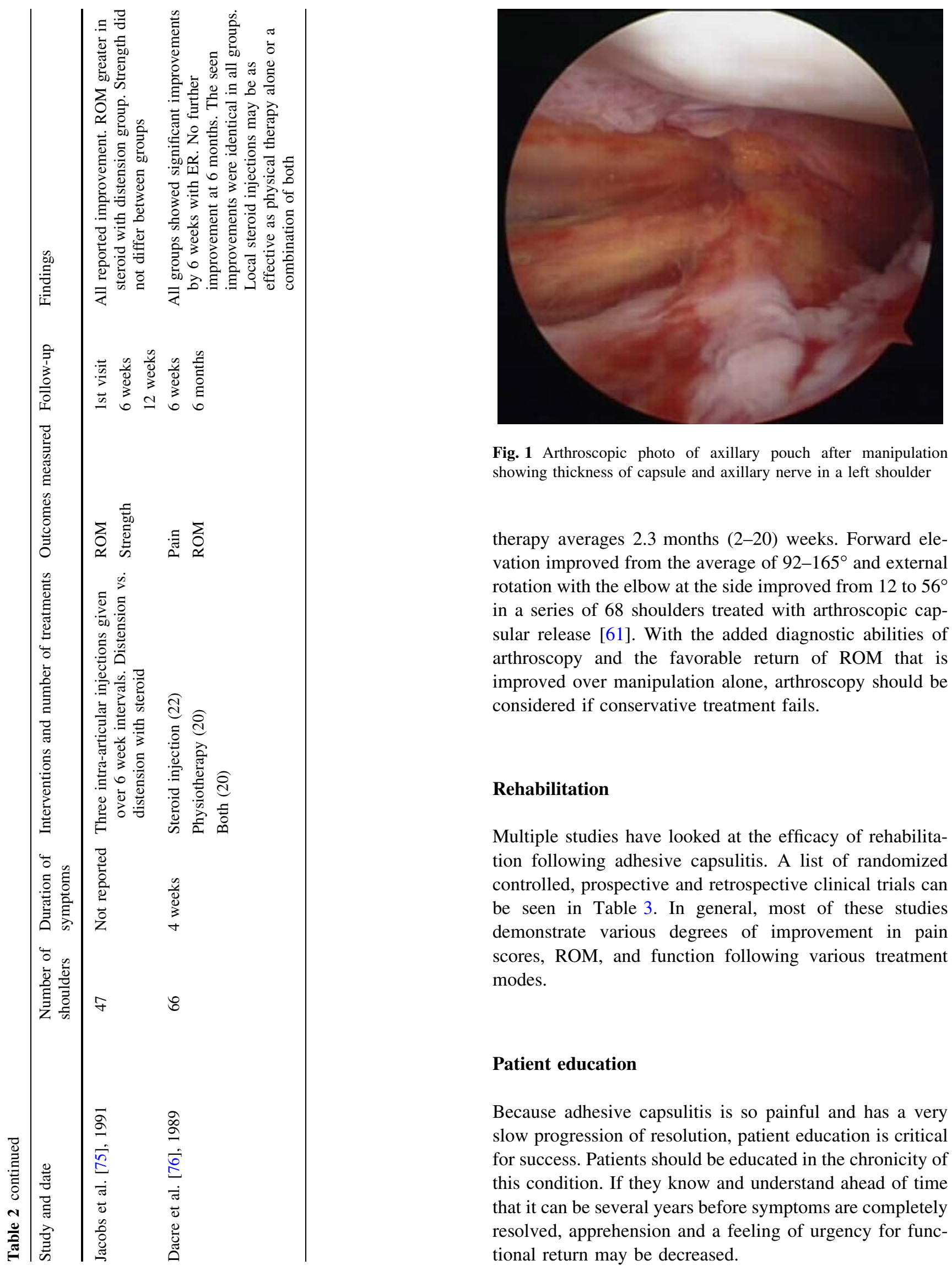




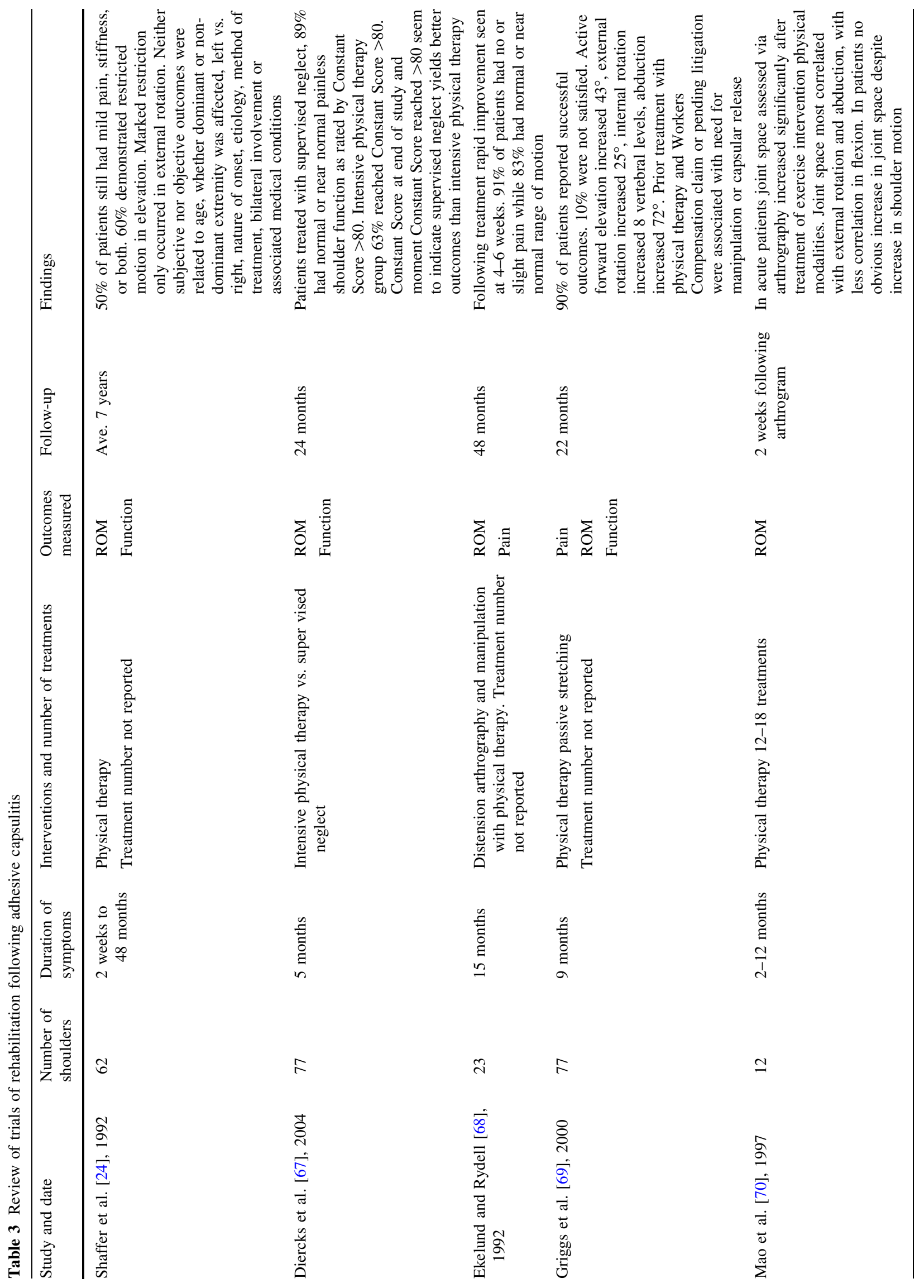




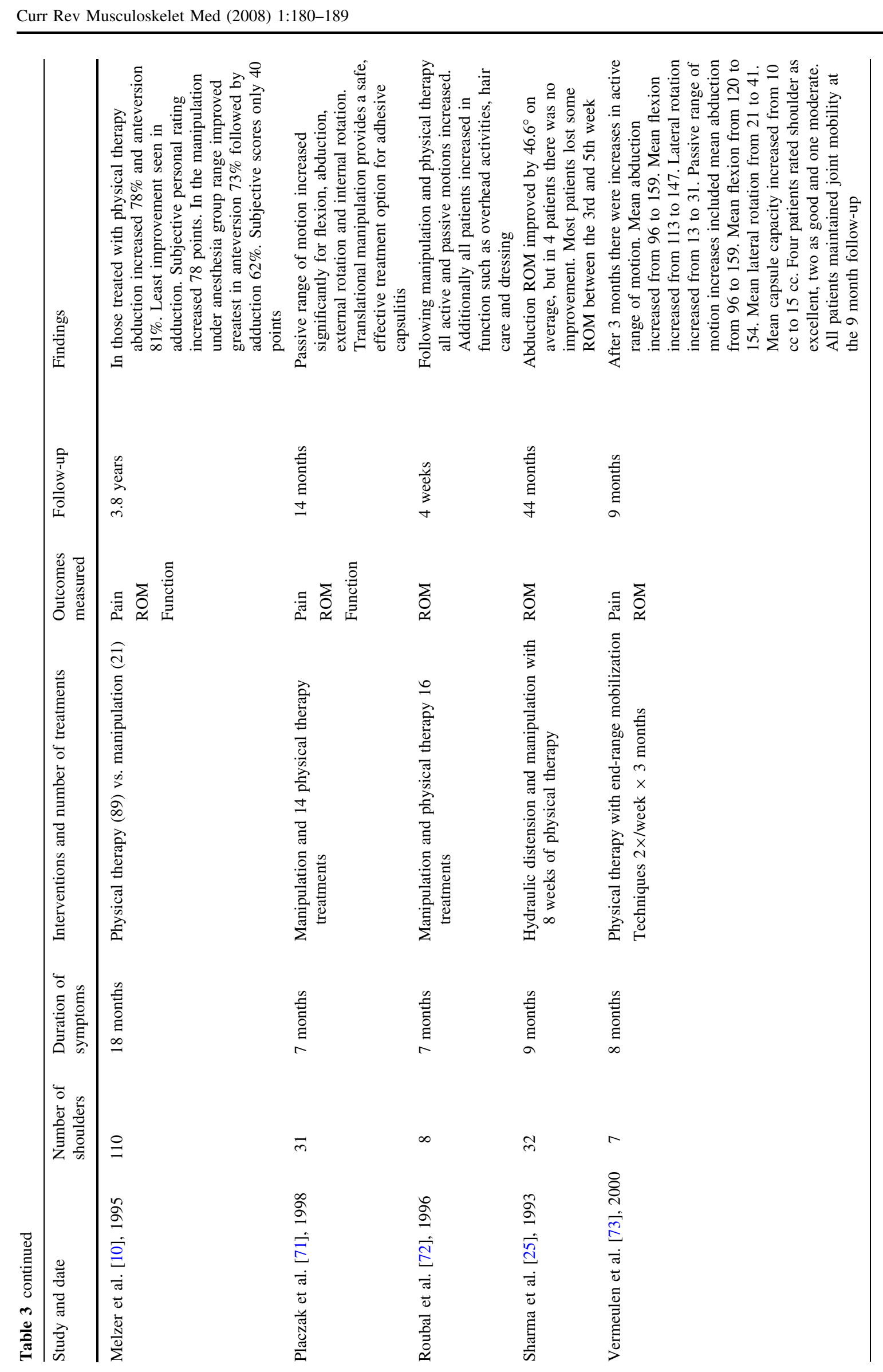




\section{Summary}

Adhesive capsulitis is a common shoulder condition. There is often a delay of patient presentation, and sometimes delay in diagnosis as it can share symptoms with many other shoulder conditions. Typical history is that of minor or no trauma with the gradual progression of pain and loss of ROM. The hallmark of physical examination is loss of both passive and active ROM without degenerative changes on X-ray. A combination of pharmacological, rehabilitative, and/or surgical treatment is commonly helpful for the patient afflicted with adhesive capsulitis. Comorbid factors may play a key role in length and amount of recovery.

Open Access This article is distributed under the terms of the Creative Commons Attribution Noncommercial License which permits any noncommercial use, distribution, and reproduction in any medium, provided the original author(s) and source are credited.

\section{References}

1. Anton HA. Frozen shoulder. Can Fam Physician. 1993;39:17728.

2. Fareed DO, Gallivan WR. Office management of frozen shoulder syndrome. Clin Orthop. 1989;242:177-83.

3. Loyd JA, Loyd HM. Adhesive capsulitis of the shoulder: arthrographic diagnosis and treatment. South Med J. 1983;76:879-83.

4. McClure PW, Flowers KR. Treatment of limited shoulder motion: a case study based on biomechanical consideration. Phys Ther. 1992;72(12):929-36.

5. Murnaghan JP. Adhesive capsulitis of the shoulder: current concepts and treatment. Orthopedics. 1988;11(1):153-8.

6. Neviaser JS. Adhesive capsulitis and the stiff and painful shoulder. Orthop Clin North Am. 1980;11:327-31.

7. Parker RD, Rroimson AL, Arsham NZ. Frozen shoulder. Part II: treatment by manipulation under anesthesia. Orthopedics. 1989;12:989-90.

8. Rizk TE, Christopher RP. Adhesive capsulitis (frozen shoulder): a new approach to its management. Arch Phys Med Rehabil. 1983;64:29-33.

9. Rizk TE, Pinals RS. Frozen shoulder. Semin Arthritis Rheum. 1982;11:440-51.

10. Melzer C, Wallny T, Wirth $\mathrm{CH}$, Hoffman S. Frozen shoulder: treatment and results. Arch Orthop Trauma Surg. 1995;114:8791.

11. Bridgman JF. Periarthritis of the shoulder and diabetes mellitus. Ann Rheum Dis. 1972;31:69-71.

12. Lesquesne M, Dang N, Benasson M, Mery C. Increased association of diabetes mellitus with capsulitis of the shoulder and shoulder-hand syndrome. Scand J Rheumatol. 1977;6:53-6.

13. Lundberg BJ. The frozen shoulder. Acta Orthop Scand. 1969;119:1-59.

14. Pal B, Anderson J, Dick WC, Griffiths ID. Limitation of joint mobility and shoulder capsulitis in insulin- and non-insulin dependent diabetes mellitus. Br J Rheumatol. 1986;25:147-51.

15. Sattar MA, Luqman WA. Periarthritis: another duration related complication of diabetes mellitus. Diabetes Care. 1985;8:507-10.

16. Grey R. Brief note: the natural history of "idiopathic frozen shoulder". J Bone Joint Surg. 1978;60A:564.

17. Reeves B. The natural history of the frozen shoulder syndrome. Scand J Rheumatol. 1975;4:193-6.
18. Codman EA. Ruptures of the supraspinatus tendon and other lesions in or about the subacromial bursa. In: Codman EA, editor. The shoulder. Boston: Thomas Todd; 1934. p. 216-24.

19. Watson-Jones R. Simple treatment of stiff shoulders. J Bone Joint Surg Br. 1963:45:207-13

20. Wither RJW. The painful shoulder: review of 100 personal cases with remarks on the pathology. J Bone Joint Surg Br. 1949;31:414-7.

21. Bulgen DY, Binder AI, Hazleman BL, Dutton J, Roberts S. Frozen shoulder: a prospective clinical study with an evaluation of three treatment regimens. Ann Rheum Dis. 1984;43:353-60.

22. Clarke GR, Willis LA, Fish WW, Nichols PJR. Assessment of movement at the glenohumeral joint. Rheumatol Rehabil. 1975;14:39-46.

23. Binder AI, Bulgen DY, Hazleman BL, Roberts S. Frozen shoulder: a long-term prospective study. Ann Rheum Dis. 1984;43:361-4.

24. Schaffer B, Tibone JE, Kerlan RK. Frozen shoulder: a long-term follow-up. J Bone Joint Surg Am. 1992;74:738-56.

25. Sharma R, Bajekal R, Bhan S. Frozen shoulder syndrome: a comparison of hydraulic distension and manipulation. Int Orthop. 1993;17:275-8.

26. Greene WB. Essentials of musculoskeletal care. 2nd ed. Rosemont, IL: American Academy of Orthopedic Surgeons; 2001.

27. Bridgman JF. Periarthrits of the shoulder in diabetes mellitus. Ann Rheum Dis. 1972;74:738-46.

28. Bunker TD, Anthony PP. The pathology of frozen shoulder. A Dupuyten-like disease. J Bone Joint Surg Br. 1995;77:677-83.

29. Wohlgethan J. Frozen shoulder in hyperthyroidism. Arthritis Rheum. 1987;30:936-9.

30. Bowman C, Jeffcoate WJ, Pattrick M, Doherty M. Bilateral adhesive capsulitis, oligoarthritis and proximal hypothyroidism. Br J Rheum. 1988;27:62-4.

31. Choy E, Corkill M, Gibson T, Hicks B. Isolated ACTH deficiency presenting with bilateral frozen shoulder. $\mathrm{Br} \mathrm{J}$ Rheum. 1991;30:226-7.

32. Riley D, Lang A, Blair R, Birnbaum A, Reid B. Frozen shoulder and other shoulder disturbances in Parkinson's disease. J Neurol Neurosurg. 1989;52:63-6.

33. Boyle-Walker K, Gabard GL, Bietsch E, Masek-Van Arsdale DM, Robinson DL. A profile of patients with adhesive capsulitis. J Hand Ther. 1997;10:222-8.

34. Wadsworth C. Frozen shoulder. Phys Ther. 1986;66:1878-83.

35. Jayson M. Frozen shoulder: Adhesive capsulitis. Br Med J. 1981;283:1005-6.

36. Tuten HR, Young DC, Douoguih WA, Lenhardt KM, Wilkerson JP, Adelaar RS, et al. Adhesive capsulitis of the shoulder in male cardiac surgery patients. Orthopedics. 2000;23:693-6.

37. Pineda C, Arana B, Martinez-Lavin M, Dabague J. Frozen shoulder triggered by cardiac catheterization via the brachial artery. Am J Med. 1994;96:90-1.

38. Bruckner RE, Nye CJ. A prospective study of adhesive capsulitis of the shoulder in a high risk population. Q J Med. 1981;198:191-204.

39. Patten C, Hillel A. The 11th nerve syndrome. Arch Otolaryngol Head Neck Surg. 1992;119:215-20.

40. Wolf JM, Green A. Influence of comorbidity on self-assessment instrument scores of patients with idiopathic adhesive capslitis. J Bone Joint Surg Am. 2002;84:1167-73.

41. Malone T, Hazle C. Rehabilitation of adhesive capsulitis. In: Ellenbecker TS, editor. Shoulder rehabilitation. Non-operative treatment. New York: Thieme; 2006.

42. Sandor R. Adhesive capsulitis. Optimal treatment of 'frozen shoulder'. Phys Sportsmed. 2000;28:23-9.

43. Hazleman BL. Frozen shoulder. In: Rockwood CA Jr, Matsen FA III, editors. The shoulder. 2nd ed. Philadelphia: WB Saunders; 1990. 
44. Harryman DT, Lazurus MD, Rozencwaig R. The stiff shoulder. In: Rockwood Cam Matsen FA, Wirth MA, Lippitt SB, editors. The shoulder. 3rd ed. Philadephia: Saunders; 2004.

45. Mangine RE, Heckmann T, Eifert-Mangine M. Alternative techniques for the motion-restricted shoulder. In: Andrews J, Wilk K, editors. The athletes shoulder. New York: Churchill Livingstone; 1994.

46. Eustace JA, Brophy DP, Gibney RP, Bresnihan B, FitzGerald O. Comparison of accuracy of steroid placement with clinical outcome in patient's with shoulder symptoms. Ann Rheum Dis. 1997;56:59-63.

47. Jones A, Regan M, Ledingham J, Pattrick M, Manhire A, Doherty M. Importance of placement of intra-articular steroid injections. Br Med J. 1993;307:1329-30.

48. Rizk TE, Gavant ML, Pinals RS. Treatment of adhesive capsulitis (frozen shoulder) with arthrographic capsular distension and rupture. Arch Phys Med Rehabil. 1994;75:803-7.

49. Dodenhoff RM, Levy O, Wilson A, Copeland SA. Manipulation under anesthesia for primary frozen shoulder: Effect on early recovery and return to activity. J Shoulder Elbow Surg. 2000; 9:23-6.

50. Andersen NH, Johannsen HV, Sneppen O, Sojbjerg JO. Frozen shoulder arthroscopy and manipulation in general anesthesia, followed by early passive mobilization. Ugeskr Laeger. 1996;15:147-50.

51. Harryman DT, Matsen F, Sidles JA. Arthroscopic management of refractory shoulder stiffness. Arthroscopy. 1997;13:133-47.

52. Harryman DT. Shoulders frozen and stiff. Instr Course Lect. 1993;42:247-58.

53. Ogilvie-Harris DJ, Wiley AM. Arthroscopic surgery of the shoulder. A general appraisal. J Bone Joint Surg Br. 1986; 68:201-7.

54. Ogilvie-Harris DJ, Biggs DL, Fitsialos DP, Mackay M. The resistant frozen shoulder. Manipulation versus arthroscopic release. Clin Orthop. 1995;319:238-48.

55. Ogilvie-Harris DJ, Myerthall S. The diabetic frozen shoulder. Arthroscopy. 1997;13:1-8.

56. Warner JJP, Allen A, Marks PH, Wong P. Arthroscopic release for chronic refractory adhesive capsulitis of the shoulder. J Bone Joint Surg Am. 1996;78:1808-15.

57. Pollock RG, Duralde XA, Flatow EL, Bigliani LU. The use of arthroscopy in the treatment of resistant frozen shoulder. Clin Orthop. 1994;304:30-6.

58. Pearsall AW, Osbar DC, Speer KP. An arthroscopic technique for treating patients with frozen shoulder. Arthroscopy. 1999;15: $2-11$.

59. Winters JC, Sobel JS, Groenier KH, Arendzen HJ, Meyboom-de Jong B. Comparison of physiotherapy, manipulation, and corticosteroid injection for treating shoulder complaints in general practice: randomized, single blind study. Br Med J. 1997;314: 1320-5.

60. van der Windt D, Koes BW, Deville W, Boeke AJP, de Jong BA, Couter LM. Effectiveness of corticosteriod injection versus physiotherapy for treatment of painful stiff shoulder in primary care: randomized trial. Br Med J. 1998;317:1292-6.

61. Nicholson G. Arthroscopic capsular release for stiff shoulders. Effect of etiology on outcomes. Arthroscopy. 2003;19:40-9.

62. Blockey A, Wright J. Oral cortisone therapy in periarthritis of the shoulder. Br Med J. 1954;1:1455-7.

63. Kessel L, Bayley I, Young A. The upper limb: the frozen shoulder. Br J Hosp Med. 1981;25:334-9.

64. Buchbinder R, Hoving JL, Green S, Hall S, Forbes A, Nash P. Short course prednisolone for adhesive capsulitis (frozen shoulder or stiff painful shoulder): a randomized, double blind, placebo controlled trial. Ann Rheum Dis. 2004;63:1460-9.

65. Carette S, Moffet H, Tardif J, Bessette L, Morin F, Fremont P, et al. Intraarticular corticosteroids, supervised physiotherapy, or a combination of the two in the treatment of adhesive capsulitis of the shoulder. Arthritis Rheum. 2003;48:829-38.

66. Ryans I, Montgomery A, Galway R, Kernohan WG, McKane R. A randomized controlled trial of intra-articular triamcinolone and or physiotherapy in shoulder capsulitis. Rheumatology. 2005; 44:529-35.

67. Diercks RL, Stevens M. Gentle thawing of the frozen shoulder: a prospective study of supervised neglect versus intensive physical therapy in seventy-seven patients with frozen shoulder syndrome followed up for two years. J Shoulder Elbow Surg. 2004;13: 499-502.

68. Ekelund AL, Rydell N. Combination treatment for adhesive capsulitis of the shoulder. Clin Orthop. 1992;282:105-9.

69. Griggs SM, Ahn A, Green A. Idiopathic adhesive capsulitis: a prospective functional outcome study of non-operative treatment. J Bone Joint Surg Am. 2000;82:1398-407.

70. Mao CY, Jaw WC, Cheng HC. Frozen shoulder: correlation between response to physical therapy and follow-up shoulder arthrography. Arch Phys Med Rehabil. 1997;78:857-9.

71. Placzek JD, Roubal PJ, Freeman DC, Kulig K, Nasser S, Pagett BT. Long-term effectiveness of translational manipulation for adhesive capsulitis. Clin Orthop Relat Res. 1998;356:181-91.

72. Roubal PJ, Dobritt D, Placzk JD. Glenohumeral gliding manipulation following interscalene brachial plexus block in patients with adhesive capsulitis. J Orthop Sports Phys Ther. 1996;24: 66-77.

73. Vermeulen HM, Obermann WR, Burger BJ, Kok GJ, Rozing PM, van den Ende CHM. End-range mobilization techniques in adhesive capsulitis of the shoulder joint: a multiple-subject case report. Phys Ther. 2000;80:1204-13.

74. Rizk TE, Pinals RS, Talaiver AS. Corticosteroid injections in adhesive capsulitis: investigation of their value and site. Arch Phys Med Rehabil. 1991;72:20-2.

75. Jacobs LGH, Barton MAJ, Wallace WA, Ferrousis J, Dunn NA, Bossingham DH. Intra-articular distension and steroids in the management of capsulitis of the shoulder. $\mathrm{Br}$ Med J. 1991;302:1498-501.

76. Dacre JE, Beeney N, Scott DL. Injections and physiotherapy for the painful stiff shoulder. Ann Rheum Dis. 1989;48:322-5. 